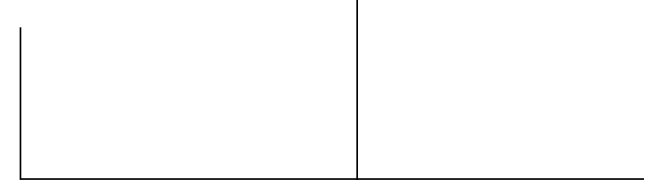

Rev. Latinoam. Psicop. Fund. VII, 2, 130-146

\title{
A noção de perda de contato vital com a realidade e suas aplicações em psicopatologia*
}

Eugène Minkowski

\section{I - O contato vital com a realidade}

Propomos expor neste trabalho nosso modo de conceber o distúrbio essencial da esquizofrenia, assim como os mecanismos psicopatológicos que determinam as particularidades dessa afecção.

Kraepelin havia chegado a uma noção sintética, muito vasta, da demência precoce, resultado de uma fusão de formas clínicas particulares que, no período anterior, tinham sido consideradas mais ou menos independentes umas das outras, como a catatonia, a hebefrenia e a demência paranóide. As formas ditas simples da demência precoce vieram juntar-se a elas.

Essa síntese coloca um novo problema. Devido à fusão, numa mesma noção, de formas clínicas em aparência inteiramente diferentes, os sintomas e mesmo as síndromes, supostamente características para cada uma delas, perdiam seu valor. Os sintomas são, como diz Kraepelin, intercambiáveis, mais ou menos inconstantes e levam a estados terminais idênticos. Então todos devem ter algo em comum, sendo apenas a expressão mais ou menos acidental de

* Tradução de Martha Gambini. Revisão técnica pelo Prof. Dr. Mário Eduardo Costa Pereira (Laboratório de Psicopatologia Fundamental-FCM/Unicamp). Publicado originalmente em Para além do racionalismo mórbido (no prelo, São Paulo: Escuta). 
um processo mórbido subjacente, sempre o mesmo. É assim que nasce a necessidade de referir toda a riqueza dos sintomas e quadros clínicos que a demência precoce hoje engloba a um distúrbio fundamental, e precisar sua natureza.

Evidentemente, esse distúrbio não pode ser buscado entre os sintomas clínicos ordinários, como as alucinações, as idéias delirantes, as manifestações catatônicas ou os estados de excitação e de depressão. Esses sintomas não têm nada de constante ou característico, como acabamos de ver. Devendo constituir sua base comum, o distúrbio fundamental não pode ser encontrado entre eles. Ele tem que ser procurado fora deles, num outro plano. Os esforços para concluir a síntese da demência precoce e para torná-la uma verdadeira entidade nosológica voltaram-se então, de modo totalmente natural, para as funções psíquicas elementares. É aqui que se esperou encontrar a chave desse comportamento particular que todos os dementes precoces apresentam, apesar das infinitas variedades que os distinguem entre si, do ponto de vista sintomático.

No entanto, as noções correntes da psicologia mostram-se rapidamente insuficientes. Tomando como ponto de partida a tríade tradicional: inteligência, sentimento, vontade, percebemos que o distúrbio em questão não pode ser reduzido a nenhuma dessas faculdades. Nem a abulia, nem a indiferença ou a falta de emotividade, e ainda menos o enfraquecimento intelectual são característicos da demência precoce. Trata-se, antes, de eclipses eletivas de cada uma dessas faculdades, que se produzem em relação a certas situações ambientais, e não de sua abolição global.

Então, as concepções psicopatológicas se deslocam. Elas se orientam para os fatores reguladores do psiquismo, para as faculdades superiores. O próprio Kraepelin, após ter falado de um enfraquecimento dos móveis efetivos do querer e de uma perda da unidade interior, liga esses dois distúrbios a uma fraqueza das idéias, dos sentimentos e das tendências de ordem geral. Ele fala, nesse sentido, de um distúrbio da abstração. Este teria como conseqüência a incapacidade de transformar as percepções em idéias mais abstratas; os sentimentos inferiores em sentimentos de ordem mais geral; as impulsões isoladas em tendências mais constantes. Kraepelin esboça até uma hipótese psicofisiológica da demência precoce, localizando essa faculdade de abstrair nas camadas microcelulares superiores da corticalidade. ${ }^{1}$ Masselon, por sua vez, coloca em primeiro plano os distúrbios de atenção e compara a atitude dos dementes precoces com uma perpétua distração. Weygand, fazendo suas as noções de Wundt, fala de

1. Traité, $8^{\mathrm{a}}$ edição, p. 745-9 e p. 905. 
demência aperceptiva. Entretanto, nenhuma dessas concepções, referindo-se às funções superiores do psiquismo, mantém-se por muito tempo. Incapazes de traduzir o distúrbio essencial da demência precoce, elas cada vez mais cedem lugar a noções de um tipo diferente.

Expressões como "discordância” (Chaslin), "ataxia intrapsíquica” (Stransky), “desarmonia intrapsíquica” (Urstein), "perda da unidade interior” (Kraepelin), “dissociação” (Claude e Levy-Valensi), “esquizofrenia” (Bleuler) implicam a idéia de que o prejuízo não teria atingido uma ou outra dessas funções, mas sim sua coerência, seu jogo harmonioso, em seu conjunto. Para empregar uma imagem, o distúrbio essencial não altera uma ou várias faculdades, qualquer que seja sua ordem na hierarquia das funções, mas reside muito mais entre elas, no espaço "intersticial”. No entanto, todas essas expressões não são, no fundo, por elas mesmas, senão uma constatação de fato, uma designação da desordem particular que os dementes precoces ou esquizofrênicos apresentam. Isso já é muito, pois, desse modo, os distúrbios discordantes são claramente separados da verdadeira demência. Mas enquanto psicólogo - e todos nós o somos em psiquiatria - não poderíamos parar por aí. Chaslin, por exemplo, vê na hebefrenia atenuada um estado discordante das faculdades psíquicas. Mas em virtude de que fatores se estabelece então, no estado normal, a corcordância dessas mesmas faculdades? É essa a questão que se coloca, e que por enquanto fica sem resposta. Ainda não conseguimos ter uma idéia clara do distúrbio fundamental da demência precoce, não sabendo ainda a qual fator do psiquismo normal ele deva ser referido.

É então que nos vêm em auxílio as comparações e metáforas. Dir-se-ia que elas se impõem por si mesmas quando se trata de colocar em relevo os traços essenciais da demência precoce. Kraepelin fala de "uma orquestra sem maestro"; Chaslin de "uma máquina sem combustível”, que quanto à sua capacidade de funcionar, é claro que difere de uma máquina deteriorada. O sr. Anglade, com quem tivemos a sorte de discutir essas questões, dizia que não empregava mais a expressão "demência precoce"; em seu lugar, falava simplesmente de doentes dissociados. Para caracterizar seu estado, ele os comparava a um livro sem encadernação; as páginas se misturaram: o volume tornou-se ilegível, e, no entanto, todas as páginas estão lá, nenhuma está faltando; é muito diferente de um livro em que elas tivessem sido definitivamente rasgadas. Nós mesmos, tentando fazer uma idéia do processo esquizofrênico, nos detivemos, mais de uma vez, diante da seguinte imagem; um edifício é feito de tijolos e cimento, e os tijolos podem se desmanchar, assim como o cimento; o edifício não fica mais de pé, desaba, em ambos os casos; entretanto, trata-se, nos dois casos, de coisas diferentes; as ruínas não serão as mesmas, não terão nem o mesmo aspecto, nem o mesmo valor; será mais fácil reconstruir uma nova casa com os tijolos intactos do que apenas com o pó. 
Essas metáforas traduzem, da melhor forma, a necessidade cada vez mais urgente de se separar inteiramente o processo esquizofrênico do enfraquecimento intelectual. Mas, além disso, elas parecem apreender bem mais de perto o verdadeiro caráter da esquizofrenia, do que todas as definições psicológicas que enumeramos até agora.

Nosso espírito de precisão, contudo, se rebela. Para ele não é possível considerar essas metáforas senão como passatempo, mais ou menos engenhoso e divertido. Na sua opinião, o acesso da ciência, pelo menos da verdadeira, ou seja, da ciência exata, deveria ser-lhe negado para sempre. E, no entanto, um dos maiores filósofos contemporâneos, o sr. Bergson, não nos lembrou, uma vez mais, que todo um lado de nossa vida, e não o menos importante, escapava inteiramente do pensamento discursivo? Os dados imediatos da consciência, os mais essenciais, pertencem a essa ordem de fatos. Eles são irracionais. E não é por isso que deixam de fazer parte de nossa vida. Não existe qualquer razão para sacrificá-los ao espírito de precisão. Ao contrário, é preciso tentar apreendê-los ao vivo. A psicologia, país desértico até hoje, calcinada pelos raios excessivamente ardentes da ciência exata, talvez se transforme numa pradaria verdejante e fértil, talvez finalmente se aproxime da vida. Não deveríamos nos inspirar nessa tendência no que diz respeito ao problema que nos interessa mais particularmente aqui?

É assim que surge a noção do contato vital com a realidade.

Bleuler descrevia os sintomas cardinais da esquizofrenia referindo-se à ideação, à afetividade e às volições do doente. Mas, ao mesmo tempo, graças à noção de autismo, os fatores referentes às relações com o ambiente começaram a desempenhar um papel cada vez mais importante em sua concepção. A falta de objetivos reais e de idéias diretrizes, a ausência de contato afetivo orientavam o conceito numa nova via. Todos esses distúrbios pareciam convergir para uma única noção, como tentamos mostrar: a de perda do contato com a realidade. ${ }^{2}$

O contato vital com a realidade parece, sem dúvida, se relacionar com os fatores irracionais da vida. Os conceitos ordinários, elaborados pela fisiologia e pela psicologia, como excitação, sensação, reflexo, reação motora etc., passam ao largo deles, sem mesmo tocá-los. Os cegos, os mutilados, os paralisados, podem viver em contato bem mais íntimo com o ambiente do que os indivíduos cuja vista encontra-se intacta e que têm seus quatro membros: os esquizofrênicos, pelo contrário, perdem esse contato, sem que seu aparelho sensitivo-motor, sem que sua memória, sem mesmo que sua inteligência tenham se alterado. O contato

2. E. Minkowski. “La schizophrénie et la notion de maladie mentale (Sa conception dans l' oeuvre de Bleuler)”. Encéphale, 1921. 
vital com a realidade visa muito mais o fundo mesmo, a essência da personalidade viva, em suas relações com o ambiente. E esse ambiente, para frisar novamente, não é nem um conjunto de excitações externas, nem de átomos, nem de forças ou de energias. Não; ele é essa onda móvel que nos envolve de todas as partes e que constitui o meio sem o qual não poderíamos viver. “Os acontecimentos”, como ilhas, dele emergem, vindo abalar as mais íntimas fibras de nossa personalidade, penetrando-a. E esta novamente os faz seus, vibra, como uma corda estendida, em uníssono com eles, embebe-se por sua vez, e aí reunindo os fatores que compõem sua vida íntima, reage de modo pessoal, não por contrações musculares, mas por atos, por sentimentos, por risos ou lágrimas, que vêm se colocar sobre as ondas do devir ambiente, aí se perdendo como uma gota de água, dirigindo-se ao infinito que nos escapa. É assim que se estabelece essa harmonia maravilhosa entre nós e a realidade, harmonia que nos permite seguir a marcha do mundo, sempre resguardando a noção de nossa própria vida. Não poderíamos aqui insistir mais sobre esse ponto importante. O que dissemos deveria, no entanto, bastar para pelo menos tornar provável o fato de que o contato com a realidade concerne o dinamismo íntimo de nossa vida. Os conceitos rígidos de nosso pensamento espacial não poderiam atingi-lo. Aqui, as metáforas parecem muito mais adequadas do que as definições. São elas que são chamadas a tornar mais clara a noção do contato vital com a realidade.

Noção inteiramente nova? Certamente não. Felizmente, íamos mesmo dizer, pois as modificações excessivamente revolucionárias em geral não valem muito. Janet, em sua teoria da psicastenia, fala longamente da função do real. Essa noção, mesmo não sendo idêntica à do contato vital com a realidade, tem com ela muitos pontos em comum. E a circunstância de que duas vias diferentes se orientem na mesma direção, não provaria que trata-se aí de coisas verdadeiras e importantes que, por assim dizer, estão "no ar" em nosso tempo?

A noção do contato vital com a realidade e a interpretação da esquizofrenia como perda desse contato nos dão involuntariamente uma sensação de conforto. Pois ela não poderia parecer mais simples e plausível. O iniciante assimila-a rapidamente e sem dificuldade. Entusiastas, quase seríamos levados a dizer que essa noção é o principal resultante da evolução do conceito de demência precoce.

Mas será que toda essa poderosa corrente da psiquiatria clínica só teria conduzido, no final das contas, a uma noção de psicologia e psicopatologia gerais? Não acreditamos nisso. Ela ainda pode prestar outros serviços, como veremos mais tarde. Mas mesmo se não fosse o caso, essa nova aquisição da ciência não seria negligenciável. Aliás, não é essa a sorte de muitas outras noções clínicas em psiquiatria? Também a confusão mental deve sua origem à necessidade de se estreitar o domínio das demências. Ela substitui o grupo das demências agudas curáveis de Pinel. Defendida na França sobretudo por Delasiauve, em seguida 
ela migra para o estrangeiro. Durante sua evolução, depois de ter sofrido muitos retoques e alargado sua moldura, ela voltou a ocupar um lugar de honra em seu país natal, principalmente graças aos trabalhos de Chaslin. Finalmente, sob a impulsão de Toulouse, Mignard e Juquelier, ${ }^{3}$ ela chegou a uma noção de ordem geral, a de autocondução. Aliás, essa particularidade da evolução de nossas noções clínicas não deveria nos surpreender, pois toda entidade clínica não se torna clara e precisa somente a partir do momento em que conseguimos dar-lhe um sólido fundamento psicológico? Assim, assistimos a psiquiatria moderna se esforçar para colocar em evidência os distúrbios geradores das entidades clínicas que ela estuda.

Acredito poder reivindicar, pelo menos em parte, a paternidade da noção do contato vital com a realidade, enquanto ponto central da esquizofrenia. Evidentemente, não “inventei” em todas as suas peças essa noção. As idéias que não buscam um traço de união nem com o passado, nem com o presente, em geral não valem muito. As obras de Bergson exerceram sobre mim uma grande influência. De outra parte, encontramos a idéia de uma perturbação profunda das relações com o mundo exterior do início ao fim do livro de Bleuler sobre a esquizofrenia. Bleuler, entretanto, coloca em primeiro plano os sintomas cardinais e elementares dessa afecção, referentes à ideação, à afetividade e às volições do doente, e mesmo que insista na perda de contato com a realidade (autismo), não faz contudo dessa perda um distúrbio gerador do qual decorreriam todos os outros. O contato vital com a realidade não é para ele um fator regulador essencial da vida ao qual poderiam ser subordinadas as funções psíquicas. Fiel ao associacionismo, ele defende, em sua teoria da esquizofrenia, a opinião de que um distúrbio particular nas associações das idéias é o distúrbio primeiro dessa afeç̧ão. Busca, a seguir, uma base orgânica para esse distúrbio.

Apresentando aos alienistas franceses a noção de esquizofrenia, não pude me impedir de dar a ela uma nota pessoal. Quem poderia me censurar por isso? A análise crítica de uma obra estrangeira só pode servir de introdução ao seu estudo. Se ela conseguir suscitar o interesse do leitor por essa obra, seu objetivo foi atingido. Por outro lado, quando tentamos realmente fazer nossas as idéias de um outro, quando verdadeiramente as vivemos, sem nos contentarmos em unicamente adotá-las tal como são, nem sempre é possível a seguir nos apagar totalmente. Aliás, isso tem pouca importância. A ciência progride para além das pessoas de seus artesãos com as quais no fundo ela se preocupa muito pouco.

3. Toulose e Mignard. Revue de Psychiatrie, 1908, 1909, 1911, 1912. Annales psychologiques, junho de 1914. Toulouse, Juquelier e Mignard. Annales Médico-psychologiques, julho-agosto de 1920. 
Assim, fiz do contato vital com a realidade o ponto central da esquizofrenia. Uma certa dualidade surge daí entre a obra-prima de Bleuler e minha análise. Villey-Desmésaret colocou muito bem em evidência tal dualidade na sua tese. ${ }^{4}$

Por outro lado, o sr. Mignard ${ }^{5}$ quis ressaltar a nota pessoal que eu trouxe à noção de esquizofrenia, antes de tudo sob a influência das idéias bergsonianas. Hoje, insisto nesse ponto no interesse mesmo da discussão. Assim, por exemplo, a crítica ${ }^{6}$ de que "nós ficamos, desde o início bloqueados pelo fato de que o desequilíbrio profundo do contato com a realidade é na esquizofrenia não uma conseqüência de outros distúrbios psíquicos, mas um ponto essencial do qual decorrem, ou pelo menos a partir do qual podem se considerados de modo uniforme todos os sintomas cardeais dessa afecção mental”, essa crítica, afirmamos, com todas as conseqüências que ela comporta, visa bem mais minha concepção do que a de meu mestre.

Aliás, a noção de perda de contato vital com a realidade, enquanto distúrbio essencial da esquizofrenia, orientou minhas pesquisas numa direção que talvez não seja totalmente sem interesse. Tentaremos colocá-la em evidência nos capítulos seguintes.

\section{II - Demência intelectual e demência esquizofrênica}

Passado o entusiasmo inicial, faz-se sentir a necessidade de analisar e de situar a noção do contato vital com a realidade de uma maneira mais precisa do que foi feito até aqui. A breve fórmula de que a esquizofrenia consiste numa perda desse contato não poderia bastar por muito tempo. Queremos que ela nos dê mais. Trata-se agora de ver como podemos interpretar, desse ponto de vista, as características essenciais do processo esquizofrênico, ou seja, até que ponto essa noção pode provar-se fecunda e contribuir para o progresso de nossa ciência. Exigimos que ela não seja apenas uma hipótese explicativa, mas sim que nos sirva como hipótese de trabalho.

4. Villey-Desmésaret. “Contribution à l'étude des doctrines en médecine mentale. Essai sur les courants actuels d'idées en psychopathologie. Freud, Bleuler, Janet”. Thèse de Paris, 1924.

5. M. Mignard. "Subduction mentale morbide et réactions psychopathiques secondaires". Encéphale, maio 1925.

6. H. Claude; A. Borel e Gilbert Robin. “Démence précoce, schizomania e schizophrénie”. Encéphale, março de 1924, p. 147. 
Dizíamos agora há pouco quanta influência exerceu sobre nosso pensamento a obra de Bergson. A noção do contato vital com a realidade tornou-se, por assim dizer, o ponto de junção do esforço clínico da escola de Zurique e das idéias bergsonianas. A direção na qual era preciso tentar forçar passagem encontravase assim traçada à nossa frente. Tomamos esse caminho, fortemente convencidos de que a psicologia, e com ela a psicopatologia, só têm a ganhar com o contato com a filosofia, pois a verdadeira filosofia sempre foi uma fonte inesgotável de ensino e conhecimento de psicologia humana.

Não há necessidade de expor aqui em detalhe as idéias de Bergson, pois hoje elas são suficientemente conhecidas. Lembremos simplesmente a oposição fundamental entre a inteligência e o instinto que ele estabeleceu.

Enquanto o instinto, diz Bergson, é moldado na própria forma da vida, a inteligência é, ao contrário, caracterizada por uma incompreensão natural desta última.

A inteligência, tal como sai das mãos da natureza, tem como objeto principal o sólido inorganizado. Ela só representa claramente o descontínuo e a imobilidade. Assim, ela só se encontra à vontade na morte. Comporta-se invariavelmente como se fosse fascinada pelas contemplações da matéria inerte. Daí seu espanto quando se volta para o vivo e se encontra diante da organização.

Justamente porque tenta sempre reconstituir e reconstruir com o dado, a inteligência deixa escapar aquilo que há de novo em cada momento de uma história. Ela não admite o imprevisível. Assim, concentrada sobre o que se repete, unicamente preocupada com soldar o mesmo ao mesmo, a inteligência desvia-se da visão do tempo. Ela tem aversão pelo fluente e solidifica tudo o que tocou. Nós não pensamos o tempo real, nós o vivemos. (Bergson, Evolução criadora)

A psicopatologia não podia deixar de ser levada, cedo ou tarde, a colocar a questão sobre a possibilidade das concepções de Bergson lançarem uma nova luz nos problemas diante dos quais as noções da psicologia corrente tinha até então fracassado. Tratava-se de ver, ao mesmo tempo, até que ponto os fatos psicopatológicos podiam ser evocados para confirmar os dados evidenciados pela intuição genial do grande filósofo. No fundo, essa tentativa é natural. Os processos mórbidos, agindo freqüentemente de uma forma eletiva, dissociam, por assim dizer, as diversas funções e as mostram em estado de nudez. Muitas vezes a patologia tem sucesso ali onde a fisiologia não consegue descrever toda a complexidade dos fatores em jogo.

Na vida, a inteligência e o instinto, ou em outros termos, os fatores de nosso psiquismo relacionando-se ao sólido, ao inerte, ao espaço, por um lado, e aqueles que se referem à duração vivida, ao dinamismo, por outro, interpenetram-se mutuamente e formam um todo harmonioso. Não bastando por si só para garantir a existência do indivíduo, cada um desses dois grupos de fatores 
completa o outro, limitando, ao mesmo tempo, de modo natural e apropriado, seu campo de ação. Mas essa harmonia não poderia sofrer, sob a influência de modificações patológicas, perturbações notáveis? O instinto, por exemplo, não pode ser lesado em primeira linha? A inteligência, nesse caso, privada de seu freio natural, não buscaria suprir, bem ou mal, o instinto enfraquecido, e não poderia assim chegar a formas monstruosas? Inversamente, os elementos da inteligência não podem ser a sede da lesão primeira, com conservação ou deformação secundárias dos fatores que se relacionam com a duração? Essas questões de forma alguma levam a especulações abstratas, como alguns poderiam temer. Pelo contrário, elas conduzem, como logo veremos, a uma série de fatos, a fatos que, não estando englobados na maneira usual de se considerar os fenômenos psicopáticos, foram, talvez demais, negligenciados por nossos predecessores. Compararemos, em primeiro lugar, desse ponto de vista, os dois grandes processos mentais que a psicopatologia conseguiu descrever até agora, ou seja, o processo esquizofrênico e o enfraquecimento intelectual, ${ }^{7}$ que ambos, após uma progressão mais ou menos lenta, levam a estados terminais específicos e dessemelhantes. Muitos autores insistiram, nos últimos tempos, sobre a diferença fundamental entre esses dois grandes processos mórbidos. Entretanto, apesar da evidência dessa diferença, não é muito fácil precisá-la. Certamente podemos definir, sem inconveniente, o enfraquecimento intelectual como perda do julgamento e da memória. Mas não é isso que ocorre no déficit esquizofrênico. Trata-se de algo totalmente diferente. A palavra “demência”, ainda por vezes empregada, só traduz de modo muito imperfeito o caráter essencial desse déficit.

"Numa esquizofrenia, mesmo avançada, todas as funções elementares do psiquismo, até onde são acessíveis à exploração, mostram-se intactas. A memória, mais particularmente, é preservada nos esquizofrênicos, contrariamente aos verdadeiros dementes” (Bleuler). Muitas vezes ficamos surpresos ao encontrar nesses doentes "sob um envelope demencial, uma inteligência muito menos afetada do que se poderia pensar, como se estivesse apenas adormecida”. É que "os sintomas da loucura discordante simulam muitas vezes com toda presteza a demência. Delírio incoerente a frio, indiferença, atos bizarros de vários tipos, ou ainda inatividade completa da inteligência com ocupações tornadas de ordem inferior, estupor com atitudes bizarras, atos incoerentes etc., e apesar de tudo isso, muitas vezes nenhum sinal de enfraquecimento intelectual propriamente dito,

7. E. Minkowski e M. Tison. “Considérations sur la psychologie comparée des schhizophréniques et des paralytiques génnéraux”. Société de Psychiatrie de Paris, fevereiro de 1924. Journal de Psychologie, outubro de 1924. 
mesmo passageiro, nenhuma perda de memória, nenhum erro de julgamento”. "Contrariamente aos dementes verdadeiramente orgânicos, cujo funcionamento intelectual é muito mais defeituoso do que poderia inicialmente parecer, a impressão é de que nada está irremediavelmente perdido, que um pouco de esforço bastaria para movimentar novamente toda uma vida cerebral”. E, no entanto, tratase de grandes doentes, que "aparentemente muitas vezes se encontram reduzidos a uma vida puramente vegetativa e automática, como os idiotas” (Chaslin). ${ }^{8}$

Então o que é que lhes falta e no que eles são diferentes dos dementes, no sentido estrito da palavra?

É o problema dessa diferença crucial que tentaremos abordar agora, tomando como ponto de partida a oposição entre a inteligência e o instinto a que nos referimos acima. Esse ponto de partida, que se inspira nas idéias bergsonianas, irá conferir, além da orientação geral, um caráter particular às nossas pesquisas. Sem nos contentarmos em comparar unicamente o que falta aos doentes, trataremos ao mesmo tempo de ressaltar o que permanece intacto neles, e de precisar a diferença, em suas reações e em todo seu modo de ser, também nesse aspecto.

Começaremos o estudo dos dois processos em questão pela comparação dos últimos graus de decadência a que eles chegam.

Escolhemos entretanto, como representantes do enfraquecimento intelectual, apenas paralíticos gerais. Essa afecção apresenta, para nossas pesquisas, a vantagem de que em geral ela atinge indivíduos em plena força. Assim, neles, o enfraquecimento intelectual não aparece entremeado com outros fatores, como por exemplo as modificações fisiológicas da velhice nos dementes senis. Ele existe, por assim dizer, em estado puro.

Pergunto a um paralítico geral que chegou ao período de enlouquecimento: “Onde você está?”. Ele responde: “Aqui”. De medo que se tratasse de uma manifestação puramente verbal e automática de sua parte, insisto: "Mas aqui onde?”. O doente bate com o pé, para indicar o lugar onde se encontra, ou mostra com o indicador ou então com um gesto que indique o quarto que ele ocupa. “Ora, aqui!” ele nos diz, parecendo mesmo espantado e irritado com nossa insistência.

8. Citamos aqui as palavras de Chaslin sobre os loucos discordantes, pois essa noção visa, na maior parte, a mesma categoria de doentes que Kraepelin designa com o nome de demência precoce e Bleuler de esquizofrenia. Sobre essas diferenças existentes entre a concepção desses três autores, ver meu artigo "La génèse de la notion de schizophrénie etc.". In: Évolution psychiatrique, Payot, 1925. 
Não se trata nesse caso, de forma alguma, de uma reação contingente, mas sim de uma manifestação que encontramos nos doentes com surpreendente freqüência.

O esquizofrênico, caso responda à questão colocada, o faz em geral corretamente, mencionando o lugar onde se encontra. Mas, em contrapartida, quantas vezes nos diz que, mesmo sabendo onde está, ele não se sente no lugar que ocupa, não se sente no seu corpo, e que o "eu existo” não tem um sentido preciso para ele.

Fatores de duas ordens diferentes intervêm em nossa orientação no espaço. Os fatores de ordem estática situam os objetos, uns em relação aos outros, no espaço geométrico, onde tudo é imóvel, relativo e reversível. Mas, além disso, nós vivemos no espaço e o eu que age coloca, a todo instante, diante de si mesmo, a noção fundamental do "eu-aqui-agora”, tornando-a um ponto absoluto, um verdadeiro centro do mundo. Na vida normal, esses fatores interpenetram-se. Nossos conhecimentos e imagens mnêmicas vêm se agrupar em torno do "euaqui-agora" fundamental e nos permitem dizer, segundo as circunstâncias: "Estou agora em Paris, em Londres, ou em meu escritório”.

Em um paralítico geral, as lembranças, ou, em uma palavra, os fatores estáticos, estão ausentes. ${ }^{9}$ Ele está desorientado no espaço, no sentido corrente da palavra. No entanto, o arcabouço fundamental do "eu-aqui" permanece intacto e ativo. O esquizofrênico, ao contrário, sabe onde ele está, mas o "eu-aqui” não possui mais sua tonalidade habitual e falha.

Num estado menos avançado, observamos no paralítico geral reações de estrutura um pouco mais complexa, mas cuja natureza permanece a mesma. À questão: “De onde você veio?”, o doente responde: “De lá onde eu estava antes”. Evidentemente, ele está desorientado no espaço, incapaz de nomear o lugar de onde vem. Entretanto, o arcabouço dinâmico da mudança de lugar que se traduz pela relação: lugar $\mathrm{X}$ antes, lugar $\mathrm{Y}$ agora, permanece intacta.

À mesma categoria de fatos pertencem às manifestações seguintes:

Q. Onde você está? - R. Lá onde fiz minha toilette esta manhã. Ou ainda: lá onde estou há algum tempo.

Q. Que casa é esta? - R. É a casa onde me colocaram.

Q. Quem é este senhor? - É um senhor que está aqui.

Q. O que você está fazendo? - R. Por enquanto eu fico aqui.

Se colocarmos um paralítico geral que chegou ao período demencial diante de um espelho e perguntarmos; “Quem é esse?” Ele responde: “Eu”. Continuamos:

9. Deixamos aqui de lado a questão de se esses elementos estão destruídos de modo irreparável ou se simplesmente eles não intervêm mais utilmente, em razão de distúrbios funcionais. 
“Mas quem, eu?”. Então, ele declina seu nome e sua profissão. Essa reação é bem menos constante nos esquizofrênicos num estado avançado da afecção. Eles respondem: “eu”, e depois "minha atividade, minha personalidade”, ou ainda: é energia, ou, finalmente, ingressando imediatamente no sentido de suas idéias delirantes, dão respostas como "eu, o filho de Claude Farrère". Uma de nossas doentes responde: "Eu sei quem é”, e ela reforça várias vezes o "eu sei” para marcar bem que ela não vive essa experiência. "Eu sei quem é, ela continua, mas é uma simples constatação, não há nada dentro; é uma cara esquisita, um olhar fixo, oblíquo e glacial...”

O paralítico geral segue assim, com os últimos vestígios de sua atividade psíquica, o caminho traçado pelo eu social. O esquizofrênico, ao contrário, não o faz, e sempre mostra um grau mais ou menos grande de despersonalização. Aqui, falta a afirmação do eu.

O sentido das substituições também fica intacto, por muito tempo, no paralítico geral. Basta perguntar-lhe a data, por exemplo, para que ele pegue instintivamente o jornal a seu lado. Um paralítico geral totalmente demente responde à questão: "Em que dia estamos?” - “Não tenho nada que me diga isso”. Um outro, quando lhe perguntamos o dia de seu nascimento, responde: "Não posso dizer, porque estou sem minha aliança”. Na aliança, ele encontraria gravada não a data de seu nascimento, mas o do casamento, mas ele não percebe isso; em compensação, ele sabe que existem meios para substituir a memória que falha e os busca instintivamente.

O comportamento do esquizofrênico é completamente diferente. Muitas vezes ele sabe a data, mas essa informação não tem mais um sentido preciso para ele, que não a utiliza mais de modo adequado às exigências do ambiente. Nele, fator pragmático é o primeiro a ser atingido.

Um paralítico geral, apresentando um estado de demência profunda, responde à questão: “O que você está fazendo?” - "Eu espero os acontecimentos e faço projetos”. Um outro doente, que chegou a um grau extremo de decadência intelectual, quase não conseguindo mais falar, percebe que eu esqueci o chapéu em seu quarto e ri disso. Para o esquizofrênico, em contrapartida, nada do que é acontecimento, projeto, movimento, parece existir mais.

Essas poucas comparações estabelecem a diferença fundamental entre os estados terminais aos quais chegam o enfraquecimento intelectual, na paralisia geral, de um lado, e o processo esquizofrênico, de outro.

Não poderíamos confundi-los. São os fatores estáticos que faltam no primeiro caso, enquanto no segundo é, ao contrário, todo o dinamismo mental que arrefece.

Evidentemente, esta fórmula é demais. Sobretudo a palavra dinamismo pode prestar-se a confusões. A física também a emprega. Mas aqui, no estudo do 
movimento, como mostrou claramente Bergson, o tempo já é concebido como linha reta e assimilado assim ao espaço. Tudo o que é movimento e progressão, tudo o que é tempo real já é de início excluído dessa concepção.

$\mathrm{O}$ verdadeiro dinamismo, enquanto conjunto de fatores que se relacionam à duração vivida, é algo totalmente diferente. É desse último que estamos falando aqui. Aliás, nós o fazemos de modo imperfeito e provisório. Não poderia ser de outro modo, pois nesse domínio ainda nos falta uma base sólida. Para estabelecêla, seria preciso nada menos do que descrever e agrupar todos os fenômenos de nossa vida que se relacionam ao tempo real, e em seguida ver como eles se comportam, tanto no psiquismo normal quando no psiquismo mórbido; em uma palavra, seria necessário criar uma psicologia e uma psico-patologia do tempo vivido. Tarefa difícil, caso decidamos realizá-la, mas também tarefa indispensável para quem quer compreender a alma humana, em seu funcionamento normal e em seus desvios patológicos.

Mas enquanto não conseguimos algo melhor, pensamos que a fórmula com a qual resumimos nossas observações traduz, de modo adequado, a diferença estudada. Aliás, o contraste que estabelecemos entre os estados terminais dos paralíticos gerais e dos esquizofrênicos, pode ser levado mais longe. Ele também projeta uma luz sobre as fases anteriores dessas duas afecções e faz ressaltar, sob o ângulo adotado no início deste estudo, os traços essenciais de cada uma delas.

Comecemos pelos paralíticos gerais.

À medida que nos afastamos do período terminal, a interpretação dos fatos torna-se mais difícil. O caráter essencial, evidenciado acima, pode no entanto ser reconhecido.

O quadro fixo dos anos, dos meses, das semanas, em suma, a noção de duração mensurável, ou seja, assimilável ao espaço, muitas vezes foi abolida. Mas isto está longe de querer dizer que qualquer noção referente ao tempo desapareceu. Um doente pode contar corretamente, por ordem cronológica, o que ele fez durante a guerra, mas não sabe mais nem quando a guerra começou, nem quando terminou. A lembrança da sucessão de um certo grupo de fatos é conservada, ao passo que a faculdade de relacioná-los a um ponto fixo, a um ano determinado, parece não mais existir.

A imagem espacial da duração, então, desaparece. Os elementos que compõem a noção do tempo, privados do enquadre de uma moldura fixa, desenvolvem-se livremente, por assim dizer. Eles invadem, em sua extrema mobilidade, todo o psiquismo do indivíduo. Há apenas sucessão imediata, extrema penetração e velocidade, nas fabulações e nos projetos delirantes dos doentes.

As expressões como: daqui a pouco, imediatamente, ultimamente, em breve, ocorrem com uma surpreendente freqüência em suas falas. Uma doente 
nos fala todos os dias de seu marido que, segundo ela, virá buscá-la. Ele já está lá, sobe as escadas, vai chegar agora em seu quarto e levá-la imediatamente. Ou, ainda, são os carros que correm a oitocentos quilômetros por hora, ou viagens para a Argentina feitas em cinco minutos.

Eles vivem, poderíamos dizer, unicamente no futuro. É esse futuro que encontramos antes de tudo em seus dizeres.

Esse dinamismo invade todo o indivíduo, transborda-o, propaga-se através de todo o universo. Ocorrem então os sintomas do período delirante da paralisia geral. O doente faz projetos para o futuro imediato, projetos grandiosos, pois não conhece mais limites. ${ }^{10}$ Ele irá imediatamente às corridas de cavalo de Longchamps, depois fará a volta ao mundo. Também vai explodir todas as ilhas do oceano e depois irá buscar a lua para colocá-la em um copo. Ele é todopoderoso, sente-se capaz de fazer tudo o que se faz no mundo, transplantes, cruzamentos de animais, pode ressuscitar todos os mortos. Aliás, associa todos os seres vivos a esse desabrochar extraordinário de suas forças. Distribui seus milhões, quer que todo mundo seja feliz; leva todos os médicos e enfermeiras em seus passeios fantásticos. Irá a Roma pedir a licença de casamento para todos os padres e todas as freiras; vai libertar todos os peixes.

Aqui, tudo é movimento, e apenas movimento, desenrolando-se numa rapidez vertiginosa, não considerando qualquer obstáculo, nenhuma distância, nenhuma duração mensurável. Esse movimento invade tudo, transborda o indivíduo, apaga os limites que existem entre ele e o universo, transforma-o com o mundo ambiente em um único oceano móvel. O doente traduz esse estado de coisas na linguagem habitual, com o auxílio de idéias de grandeza absurdas, conhecidas de todo mundo.

Comparemos agora com esse quadro a maneira pela qual uma esquizofrênica, após vários anos de doença, descreve seu estado de alma: “Tudo é imobilidade a meu redor. As coisas se apresentam isoladamente, cada uma por si, sem nada evocar. Certas coisas que deveriam formar uma lembrança, evocar uma imensidade de pensamentos, montar um quadro, permanecem isoladas. Elas são mais entendidas que experimentadas. São como pantomimas, pantomimas

10. Talvez aqui resida uma das diferenças essenciais examinadas desse ponto de vista, entre o comportamento dos paralíticos gerais e o de certos maníacos. Os projetos doentios destes últimos permanecem, ao que parece, enquadrados pela duração mensurável. Eles ainda contam com o tempo no sentido ordinário da palavra, e fixam a realização de seus projetos para “amanhã”, “depois de amanhã”, ou para “daqui a alguns dias”, ao passo que o paralítico geral vive, antes de tudo, na sucessão imediata que tudo transborda. Isso, aliás, a título de simples suposição. Atualmente não nos é possível afirmar mais nada sobre este tema. 
que são representadas a meu redor, sem que eu participe delas; eu fico de fora. Possuo o raciocínio, mas falta-me o instinto da vida. Não consigo mais agir de modo suficientemente vivo. Não posso mais passar das cordas tensas para as cordas distendidas, e, no entanto, não somos feitos para viver sob o mesmo tema. Perdi o contato com toda a espécie de coisas. A noção de valor, de dificuldade das coisas, desapareceu. Não há mais uma corrente entre elas e eu não consigo mais entregar-me a elas. A meu redor há uma fixidez absoluta. Tenho ainda menos mobilidade quanto ao futuro do que para o presente e o passado. Há em mim como uma espécie de rotina que não me permite conceber o futuro. O poder criador foi abolido em mim. Vejo o futuro como repetição do passado".

Não se trata aqui, apresso-me em dizer, de uma página de romance. Não; estes são os dizeres de uma doente que passa seus dias na cama, num estado de inércia completa, e que, quando se levanta, move-se como um robô. Que tem ilusões auditivas e manifesta idéias de transformação corporal, e que finalmente, em sua casa, aproveitando de um momento de desatenção, ateou fogo nas roupas, para proporcionar-se, como ela explica, sensações vivas que lhe são totalmente ausentes.

Não seria esta a chave para a compreensão de todo o problema da esquizofrenia? Questão tanto mais plausível pelo fato de as falas de nossa doente nem de longe serem um fato isolado e excepcional. Pelo contrário, encontramos manifestações semelhantes, para não dizer idênticas, com surpreendente freqüência, nos esquizofrênicos, desde que sejamos atentos. Nós os escutaremos dizer então que "suas idéias são imóveis como estátuas", ou, ainda, que elas "são estáticas e sem tendência à realização”, ou empregar outras expressões análogas, que servem para traduzir o estatismo que os invade progressivamente e que os fazem sofrer, quando têm consciência de seu estado. Aliás, sua atitude e suas reações muitas vezes trazem a marca desse estatismo mórbido, que pode ser encontrado até em seus movimentos estereotipados que, no fundo, são apenas um eterno recomeçar, sem qualquer progressão. Não poderíamos imaginar um contraste mais pronunciado com o quadro, traçado acima, do paralítico geral.

Insistindo ainda sobre esse contraste, não fizemos, aliás, senão determinar uma diferença importante, constatada por todos aqueles que se ocuparam dessa questão. A especificidade dos estados terminais constitui, como sabemos, um dos critérios essenciais ao qual Kraepelin recorre para erigir sua noção sintética de demência precoce. Ele fala, nesses casos, de Verblödung, e eis o que o sr. Nayrac afirma, em sua tese, sobre esse termo: "Em geral, os autores franceses traduziram essa palavra por demência, o que, como veremos, produziu confusões, pois a Verblödung, designa, em nossa opinião, algo diferente da demência. Nem que seja por puro respeito ao vocábulo, achamos bom empregar um outro substantivo para designá-lo. Verblödung exprime, na linguagem corrente, o fato 
de tornar alguém tímido, envergonhado, a ponto de dar-lhe o aspecto de um retardado mental. Por falta de um equivalente francês, traduzimos Verblödung por 'parademência"”. ${ }^{11}$

Bleuler fala nos esquizofrênicos de demência afetiva e ressalta assim, uma vez mais, a diferença fundamental existente entre a decadência esquizofrênica, de um lado, e a demência intelectual ou a simples demência, de outro. Eu mesmo, dando preferência aos fatores referentes ao desenvolvimento da personalidade, ou seja, à atividade pessoal do sujeito, falei, desde meu primeiro estudo sobre a esquizofrenia, de demência pragmática. Aliás, talvez a reunião desses dois termos não seja feliz. Parece preferível suprimir totalmente aqui a palavra demência, caso ela signifique o progressivo enfraquecimento das faculdades intelectuais, e falar de déficit pragmático. De qualquer forma, o termo proposto parece ter tocado um lado essencial do problema. Encontramos uma confirmação preciosa de nosso modo de ver nas recentes pesquisas do sr. Claude e de seus alunos. Esses autores também insistiram, nos casos descritos por eles sob o nome de esquizofrenia, na discordância entre a atividade intelectual e a atividade pragmática. ${ }^{12}$

Para terminar, citemos a definição que Dide e Guiraud dão da demência precoce. ${ }^{13}$

A afecção, dizem esses autores, caracteriza-se pelo enfraquecimento inicial e precoce das fontes instintivas da vida mental, diretamente resultantes da atividade orgânica e cenestésica. As operações puramente intelectuais só são modificadas de maneira acessória: sua desordem consiste durante muito tempo em obstrução e em orientação contraditória e não em desaparecimento primitivo da função. O enfraquecimento do elã vital e da afetividade é o elemento necessário e suficiente para caracterizar a doença”. Assim, eles propõem que se substitua "Demência precoce" pelo termo "Atimornia juvenil" que expressaria bem a "perda do elã da alma cenestésica e afetiva.

Deixando de lado a interpretação organicista que Dide e Guraud dão à sua concepção, assim como a questão da existência da "alma cenestésica”, ficamos felizes em identificar, no plano psicológico, os pontos comuns entre as idéias desses dois distintos alienistas e nossas próprias pesquisas, expostas na páginas

11. P. Nayrac. Essai sur la démence paranoïde. Tese de Lille. 1923.

12. H. Claude; A. Borel e G. Robin. "Discordance entre l'activité intelectuelle e l'activité pragmatique sous l'influence d'un complexe affectif”. Annales médico-psychologiques, 1923. H. Claude; G. Robin e P. Roubenovitch. "La schizomanie simple". Société médico-psychologique, novembro de 1925. P. Roubenovitch. Contribution à l'étude de la schizomanie. Tese de Paris, 1926.

13. Dide e Guiraud. Psychiatrie du médecin praticien. Masson, 1922. 
precedentes, e isso ainda mais porque, primeiramente, essa semelhança não se reduz unicamente a simples fórmulas ou definições, mas diz respeito à valorização de fatos precisos, sobre os quais ainda falaremos, e, em segundo lugar, porque Dide e Guiraud, longe de adotar a noção bleuleriana de esquizofrenia, empregam antes o termo "demência precoce" em sua significação mais restrita. Atribuímos grande importância a essa última circunstância. A concordância de perspectivas, que existem apesar da diferença dos pontos de partida, serve de preciosa verificação. Por outro lado, as constatações de Dide e Guiraud, aplicando-se justamente ao caso de demência precoce, no sentido estrito do termo, vêm confirmar o que Kraepelin e Bleuler sempre ensinaram, ou seja, que em nenhum caso de demência precoce, independentemente do sentido em que esse termo seja empregado, não se trata de verdadeira demência, enquanto falha primitiva das funções puramente intelectuais, tal como pode ser encontrada, por exemplo, na paralisia geral. Nossa própria experiência faz com que nos alinhemos a esse ponto de vista. As curas espontâneas tardias, impossíveis de serem previstas de antemão, ocorrendo após muitos anos de doença, em sujeitos que apresentavam exteriormente todos os sinais de uma decadência completa e durável, falam no mesmo sentido. Nada melhor aqui do que recordar ainda uma vez as palavras de Chaslin, citadas acima a propósito dos loucos discordantes. 